\title{
AC 2009-270: A LEGO ROBOT PROJECT USING CONCEPT MAPS AND PEER-LED TEAMS FOR A FRESHMAN COURSE IN ENGINEERING AND ENGINEERING TECHNOLOGY
}

\section{Mehrube Mehrubeoglu, Texas A\&M University, Corpus Christi}

Dr. Mehrubeoglu received her B.S. degree in Electrical Engineering from the University of Texas at Austin, and her M.S. and Ph.D. degrees in Bioengineering and Electrical Engineering, respectively, from Texas A\&M University. After working as a research engineer and software engineer at Electroscientific Industries, where she developed new algorithms for machine vision problems, she joined Cyprus International University as the Chair of Department of Computer Engineering. After returning to Texas she taught at Texas A\&M University-Kingsville. She has been with Texas A\&M University-Corpus Christi since fall of 2005. Dr. Mehrubeoglu's areas of research include machine vision and image processing applications (digital watermarking, degraded fingerprint recognition, object detection and tracking), applications in biomedical engineering, and effective teaching pedagogies. 


\title{
A Lego Robot Project Using Concept Maps and Peer-Led Teams for a Freshman Course in Engineering and Engineering Technology
}

\begin{abstract}
In this paper, the use of concept maps is presented as they are applied to a class project in a freshmen course with engineering technology and pre-engineering students. Concept maps have been implemented in a newly designed Lego Robot Project. The Lego Robot Project consisted of four pre-designed projects each with different difficulty level to be suitable for students with different experiences. The teams were led by peers who had previously completed the project and were not taking the class, and by those who had prior experience with Lego Robots and were registered for the course.
\end{abstract}

Technical skills, such as designing, programming, and knowledge/use of sensors, as well as professional skills, such as teamwork, communication, problem solving, and leadership, were included in the concept maps. Deliverables were clearly stated. Student assessment of the Lego Robot Project learning outcomes revealed that the project greatly contributed to teamwork and student engagement (4 and 3.8, respectively, on a scale of 1 to 5). Goal setting and problem solving were ranked the lowest (3.1 and 3.2, respectively), but above neutral (3). Students who participated in the project components also performed well in the course.

The Lego Robot Project was successfully completed with the use of concept maps and peer-led teams. This paper presents the details of the project, implementation and use of concept maps, and dynamics of the peer-led teams.

\section{Introduction}

Introductory freshman courses in engineering and engineering technology curricula play an important role in recruitment and retention efforts of the department and program. Besides the technical skills to be acquired, one of the purposes of these courses is viewed to be enticing the student in the field of study, motivating them to learn more, and in turn stay with the program. In a continuously demographically changing classroom, instructors face the challenge of adjusting the content of the course and the projects such that both the lecture and laboratory assignments are suitable, interesting, and useful for all types of students; these students include traditional recent high-school graduate students, transfer students with some prior college course credit, professional students, and other mature students.

In the classical style of teaching this course, it has been observed that in the presence of experienced students in the classroom, the traditional students may get intimidated by the outside knowledge such experienced students may have acquired. Additionally, the 
experienced students usually display behavior suggestive of boredom because some of the material covered, such as professional skills, might be redundant to their education, as they have already mastered such skills through years of work experience. Therefore, the challenge for the educator remains to create worthy classroom or laboratory exercises for all students. In this paper, a Lego Robot Project designed for multiple levels of student experiences is described with its implementation through concept maps and peer-led teams to meet the needs of students at all levels.

Concept maps are receiving increasing attention due to their characteristic to visually display the concepts and outcomes of a course or assignment, and how these are connected at the program level. Concept maps help students better understand why they are performing an activity, what they will gain from the course, and how what they learn relates to their program. Concept maps are powerful tools for connecting project learning outcomes to course or program outcomes. In effect, concept maps help students see how what they learn fit in 'the big picture.'

Concept maps are tools used to represent knowledge ${ }^{1}$. Many educators have implemented concept maps in different contexts. Walker and King used concept mapping to assess students and instruction in bioengineering ${ }^{2}$. In their pilot study, the authors asked the students to draw concept maps before and after the course of study, and used these concept maps to assess student understanding of the concepts covered in the classroom. The results demonstrated that the concept maps created by the students after the material was discussed contained more detailed concepts and increased number of nodes than the initial maps, indicating students' improved learning throughout the course.

Mary et al. ${ }^{4}$ used concept maps to asses industrial engineering education by asking lower division and junior level students to create concept maps of the program. The exercise was repeated several years later with senior students, half of whom participated in the original exercise. The findings were used to assess the industrial engineering education and the gaps in the program. The senior student concept maps in general demonstrated increased conceptual understanding of the field, and the authors developed a structured rubric to measure the quality of the concept maps created by the students.

In industry, Kramer ${ }^{5}$ conducted research among engineers asking these engineers, who were domain experts, to draw concept maps to solve a problem at hand, to see if concept maps captured the engineers' approach to solving the problem and the concepts involved. The results of the study showed that concept maps assisted in memory recall of concepts that engineers used before. The engineers were also able to go back and modify the concept maps as they remembered more. The author additionally states that the concept maps can be used as guides to translate the design requirements for a project.

Morsi et al. used concept maps to validate an engineering curriculum ${ }^{6}$. Other groups have investigated the theoretical aspects of concept maps, including its effective formulation, implementation, and improvement ${ }^{7-8}$. Attarzadeh's group ${ }^{9}$ surveyed interactive concept maps and demonstrated that concept maps can be used as a tool to enhance learning and 
thinking skills. The benefits of concept maps are apparent. In this paper, their creation and application in a new Lego Robot Project assignment is described. Peer-led teams can be very effective if organized and trained ${ }^{10,11}$. In the first in-class realization of the Lego Robot Project, peer-led teams were used informally and without any mentor training, but with observed benefits to project learning outcomes.

\section{Lego Robot Project}

A new Lego Robot Project was designed specifically with the described pedagogical challenges in mind. Lego Mindstorm Robot kits were utilized in these projects. These older version Lego Mindstorm kits comprised of parts such as motors, Lego building blocks and bricks, axles, wheels, light sensors, touch sensors, a microprocessor, and an infrared receiver for downloading the Mindstorm program, with an infrared transmitter tower. The software originally ran on Windows 98 , and had to be adapted to Windows $\mathrm{XP}$ using a patch provided by the manufacturer and downloaded free from the internet.

Four projects requiring different skill levels and time commitments were designed to accommodate students with varied experiences. One beginner, two intermediate and one advanced level project was designed. The beginner level project addressed students with no prior experience with any robotic kits. The intermediate project targeted students with some experience with Lego robots. The advanced project was intended for the experienced robot builders or highly motivated students with little experience. The students were asked to pick the project which would be challenging enough for them based on their or their team leader's prior experience with robotics and robotic kits, with the condition that the project had to be completed.

Four new Lego robot projects were the "Robot Bug" (beginners), "Line Follower Robot" (intermediate), "Robotic Arm" (intermediate), and "Sorting Machine" (advanced). In this course, concept maps were introduced as a tool to assist students in understanding the conceptual relationships of their activities to the project learning outcomes in the Lego Robot Project. The relationship between the project learning outcomes and course learning outcomes was then shared with the students. As an assignment, students were asked to submit expanded (defining and describing existing concepts) or extended (adding new concepts) versions of the concept map for the project, the skeleton of which was initially provided by the instructor.

Peer leaders from the class (those with some experience with robotics and robotic kits) as well as outside class (beyond freshman level) facilitated the Lego Robot Project labs in an informal setting. The student enthusiasm and the voluntary time spent on the robots outside the allotted lab time for this three-week project demonstrated the high-level of student engagement in this project. This was also confirmed in students' learning outcomes assessment (see Learning Outcomes Assessment section.) 


\section{Project Learning Outcomes and How They Relate to Course Learning Outcomes}

The learning outcomes were identified separately for the course and the Lego Robot Project. Before introducing concept maps, the instructor identified how the project outcomes would serve the course learning outcomes. Table 1 summarizes the course learning outcomes listed on the course syllabus and the project activities and learning outcomes that meet these course objectives.

Table 1. Project Learning Outcomes and Corresponding Course Learning Outcomes

\begin{tabular}{|c|c|}
\hline $\begin{array}{c}\text { RELEVANT } \\
\text { COURSE LEARNING OUTCOMES } \\
\end{array}$ & $\begin{array}{c}\text { RELATED } \\
\text { PROJECT LEARNING OUTCOMES }\end{array}$ \\
\hline \multirow{4}{*}{$\begin{array}{l}\text { 1. Describe the roles and } \\
\text { responsibilities of engineering } \\
\text { technologists, and what are } \\
\text { expected of them }\end{array}$} & a. Use and demonstrate creativity \\
\hline & b. Participate in teamwork and team learning \\
\hline & $\begin{array}{l}\text { c. Establish good communication among } \\
\text { team members, peers and instructor }\end{array}$ \\
\hline & $\begin{array}{l}\text { d. Use problem solving skills and apply } \\
\text { engineering/scientific method of problem solving }\end{array}$ \\
\hline $\begin{array}{l}\text { 2. Analyze experiments and } \\
\text { experimental data }\end{array}$ & $\begin{array}{l}\text { Evaluate the deliverables of the project (working } \\
\text { robot, reports, oral presentation) }\end{array}$ \\
\hline $\begin{array}{l}\text { 3. Identify and apply the basic } \\
\text { principles of scientific method and } \\
\text { engineering problem solving }\end{array}$ & $\begin{array}{l}\text { Use the method of engineering/scientific problem } \\
\text { solving to achieve a working robot from building } \\
\text { blocks and program }\end{array}$ \\
\hline \multirow{4}{*}{$\begin{array}{l}\text { 4. Use hardware and software } \\
\text { tools to solve basic } \\
\text { engineering problems }\end{array}$} & a. Understand sensors \\
\hline & b. Learn basic programming skills \\
\hline & $\begin{array}{l}\text { c. Design a robot using Lego bricks, motors, sensors, } \\
\text { and other parts }\end{array}$ \\
\hline & d. Obtain hands-on experience \\
\hline \multirow{3}{*}{$\begin{array}{l}\text { 5. Demonstrate an ability to } \\
\text { communicate effectively }\end{array}$} & $\begin{array}{l}\text { a. Comprehend and follow instructions, and show } \\
\text { such accomplishment }\end{array}$ \\
\hline & b. Learn basic programming skills \\
\hline & $\begin{array}{l}\text { c. Design a robot using Lego bricks, motors, } \\
\text { sensors, and other parts }\end{array}$ \\
\hline
\end{tabular}

\section{Peer-Led Teams}

Peer-led teams have been proven to promote a positive learning environment. It is less likely that students will get intimidated by unclear concepts in the presence of peers and peer-led teams, since some students find it is easier to ask questions to peers than instructors. In the Lego Robot Project, the students were asked to form teams of two or three such that at least one of the team members was experienced in working with Lego Robots, and was responsible to lead the team. In addition, a sophomore student was invited to the class to assist during the Lego robot design, implementation and testing 
phase. The experienced outside-class peer also helped with the programming and software download to the robot microprocessor. In this first in-class realization of the Lego Robot Project, peer leading as well as its structure was left entirely up to the peer leaders. The instructor did not conduct any training of the peer leaders. Peer-leading was performed in a completely informal setting. The only guidelines the peer leaders (and the rest of the students in the course) were given were the objectives and learning outcomes of the Lego Robot Project.

\section{Concept Mapping}

Concept maps are tools used to represent knowledge ${ }^{1}$. Concept maps are intended to externalize the concepts to be learned, and in turn, improve learning ${ }^{3}$. In the Lego Robot Project, the instructor prepared a skeleton concept map whose central concept was the Lego Robot. As part of their project score (10\%), the students were asked to expand on several of the linked concepts, or extend the concept map to include new concepts.

Figure 1 displays the skeletal concept map introduced to the students.

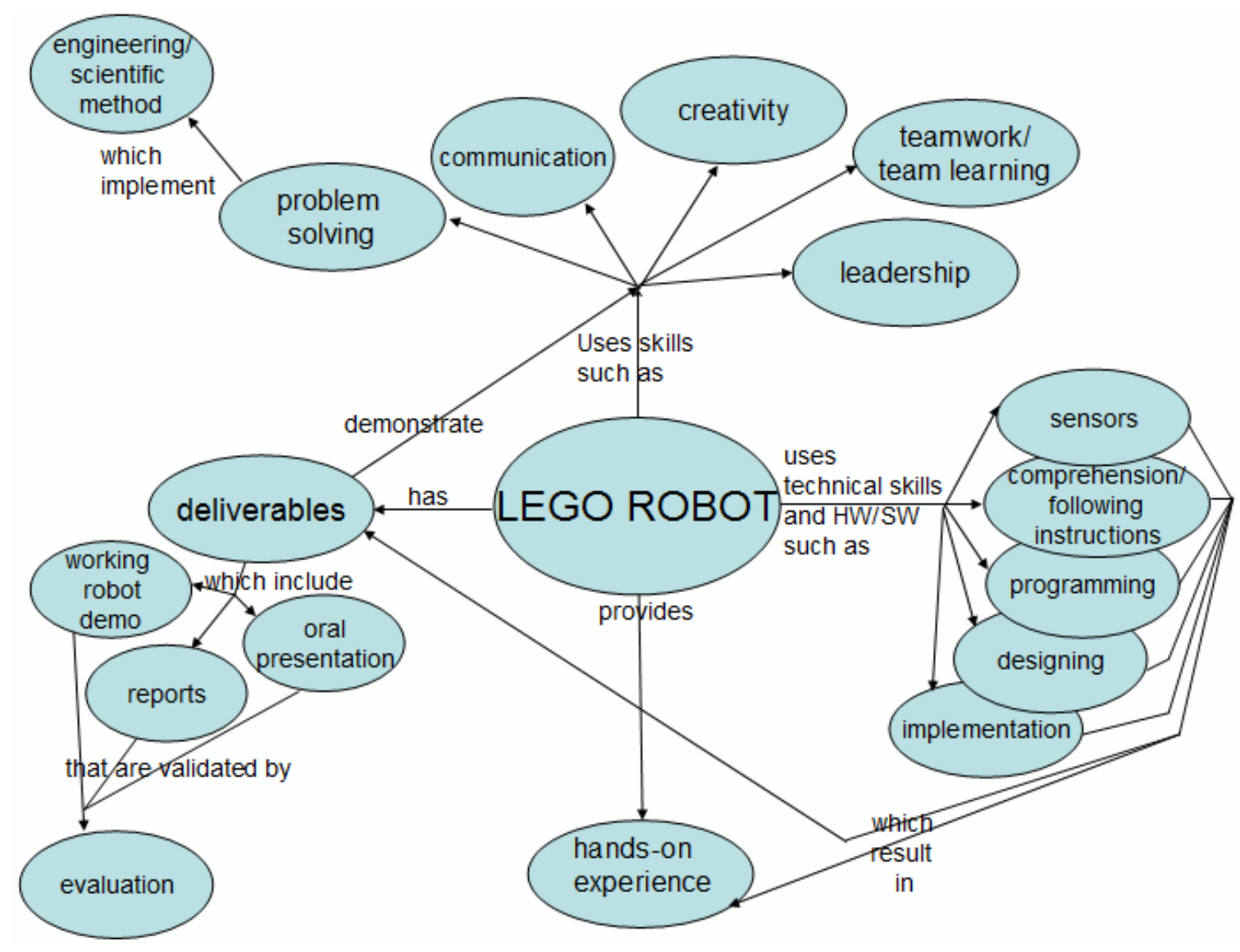

Figure 1. The Concept Map for the Lego Robot Project

In Figure 1, the students can clearly see the professional and technical skills that will be used in the Lego Robot project. The concept map also reveals how these skills are 
interrelated with hands-on experience and the deliverables for the project. The concept map above is the display of Lego Robot Project outcomes. The students were asked to extend or expand concepts on this concept map.

Some of the concepts that the students expanded include the following:

Sensors: The students were asked to list and describe the type of sensors they would use in their project. The student had to perform research to understand how some of the sensors in the kits worked.

Programming: The students were asked to describe the block based program they would prepare for their project. The students were required to learn the software programming tool for the microcontroller.

Implementation: Students described the general approach to building their robot from blocks.

Problem Solving Skills: Students listed and explained the steps of engineering method of problem solving described in one of their textbooks ${ }^{12}$. This concept was previously covered in class.

Teamwork: Students defined teamwork and explained why it was necessary.

Leadership: Students defined leadership and explained why it was needed.

Sample concepts extended by students included time management, research, and troubleshooting.

\section{Learning Outcomes Assessment}

Learning outcomes assessment was achieved via student scores on assignments and grades in the course, as well as student self assessment of the learning outcomes.

\section{Students’ Assessment of Learning Outcomes based on Activities and Concept Maps}

Figure 2 is a summary of students' self assessment of the project learning outcomes. The students were asked to evaluate the Lego Robot Project's contribution to the technical and professional skills outlined in the concept maps.

The technical skills covered all the technical learning outcomes for the project. The professional skills included teamwork, leadership, creativity, communication skills, problem solving skills, and goal setting. The students considered the project assignments, activities, and their contribution to the technical and professional skills. In addition, the project was scored on its contribution to student engagement and hands-on experience. The average class score for each of the attributes was above 3, on a scale of 1 to 5 , where 1 represented the lowest and 5 the highest. The project received the top two scores for its contribution to teamwork (4) and student engagement (3.8). Goal setting and problem 


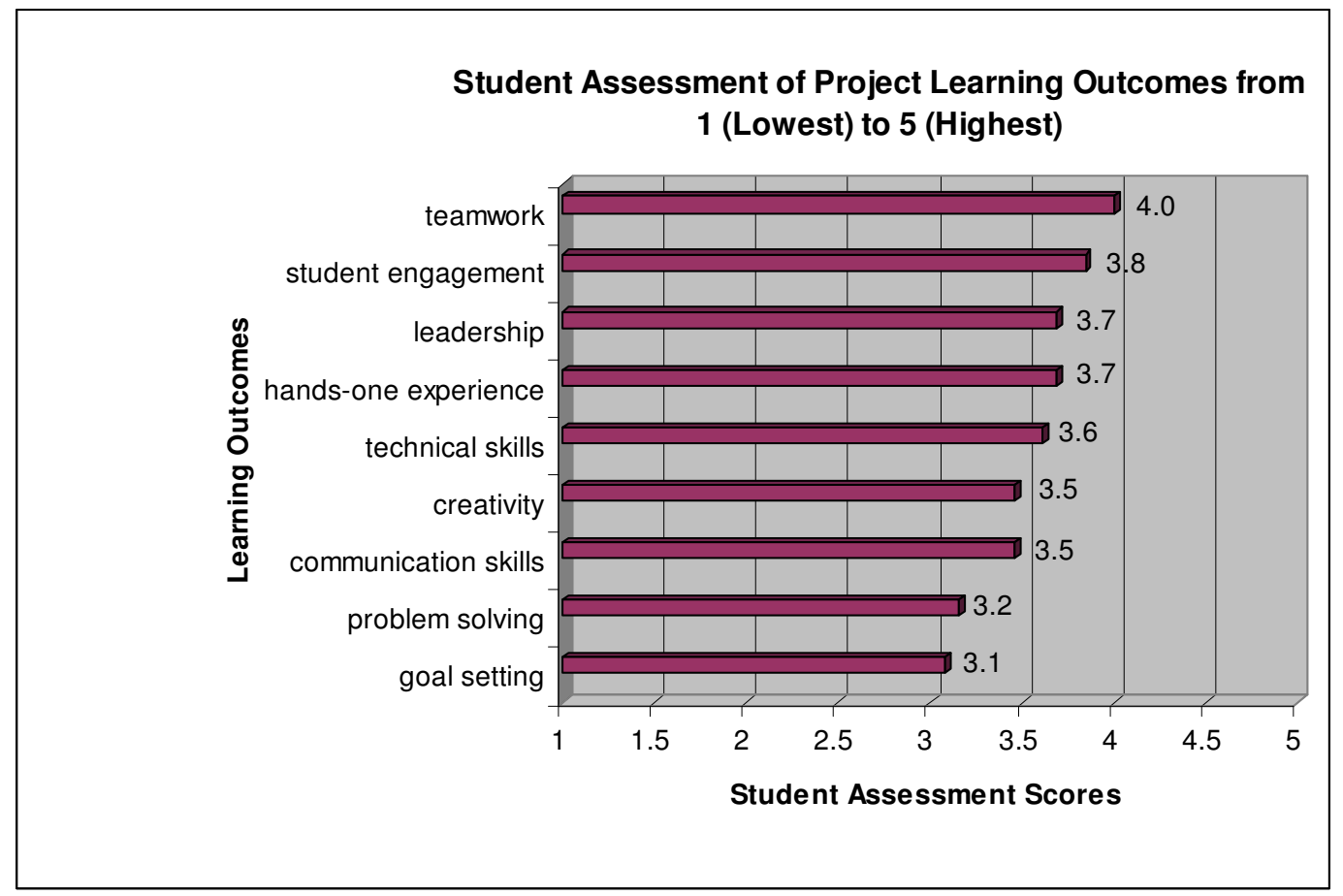

Figure 2. Students' Self Assessment of Project Learning Outcomes

solving received the bottom two scores (3.1 and 3.2, respectively) indicating that these skills require further emphasis in the class.

\section{Instructor's Assessment of Learning Outcomes}

Instructor's project assessment was based on the grades of the assignments of the project. The Lego Robot Project grading was divided into five sub-assignments: The project score was distributed through a Prelab Report (10\%), Concept Maps (10\%), Working Robot Demonstration (20\%), Oral Presentation (20\%), and Lego Robot Project Report (40\%). The Lego Robot Project constituted 5\% of the total course grade. The assignments were submitted in teams of two or three students.

Out of 19 students, 14 were registered in Introduction to Engineering Technology (IET) and five were in Foundation of Engineering (FoE) courses. The students in the IET seek Mechanical Engineering Technology and Electrical Engineering Technology degrees. The students in the FoE pursue a Mechanical Engineering degree. All students in FoE, and all but two students in IET, participated in the working robot demonstrations and oral presentations. The two students indicated personal reasons for being relatively inactive throughout the semester, although they attended classes. Their final course grade was D. Only one group in FoE submitted the Lego Robot Project Report. The other group cited time limitations and miscommunication with partners in producing a team report by the set deadline. Additional reasons included the minimal contribution of the report score to 
the final course grade. In IET, only one group, and the two non-active students mentioned above did not submit a report. Concept maps were shown and explained in the classroom by the instructor. About $42 \%$ of the students participated in the Concept Maps assignment and prelab report which was only several pages, indicating after the deadline for submission that they were not clear about the assignment, as concept maps were already clearly presented and explained in the classroom; they did not know what else they were to add.

Figure 3 displays the score distribution of eight students who participated in the Concept Maps assignment.

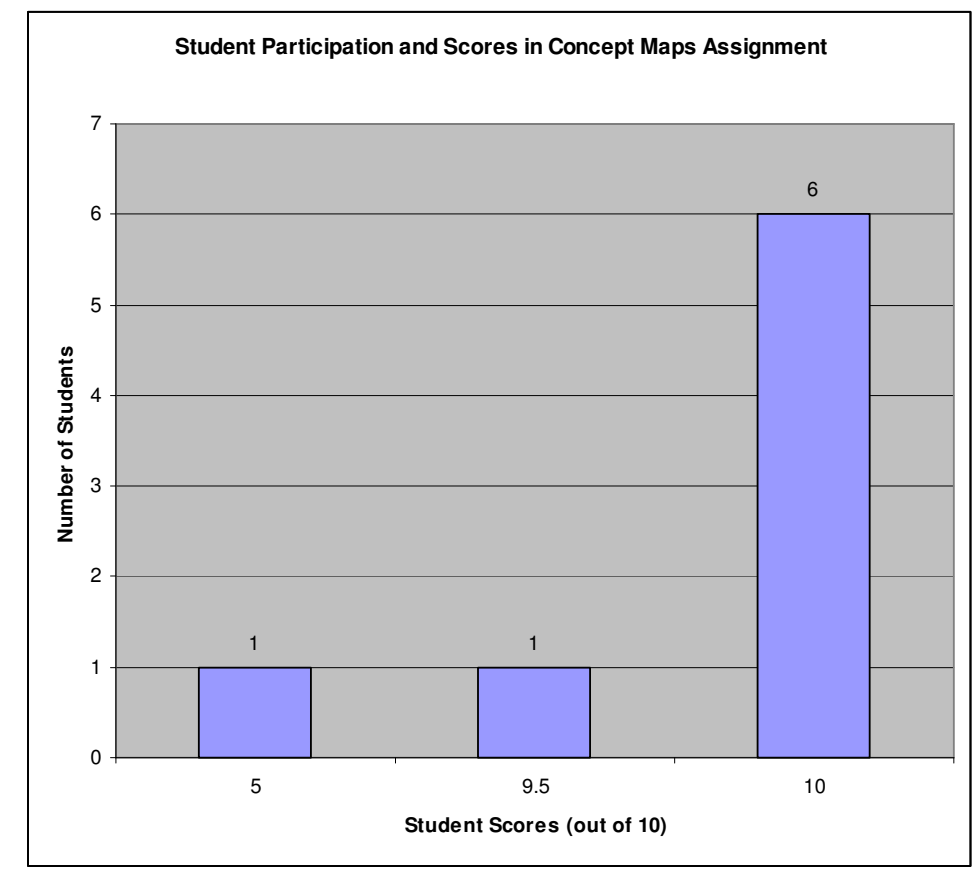

Figure 3. Students' Scores in the Concept Map Extension and Expansion Assignment (only participating student scores are included)

The significance of this figure is in its depiction of the success of participating students in the concept maps assignment, and thus, their conceptual understanding of the project activities.

Table 2 summarizes student participation in Lego Robot Project and the final grade of the students, suggesting a trend in student participation (submission of assignments) and general attitude outside the Lego Robot Project and course grade, as expected.

Considering that the Lego Robot Project was only 5\% of the overall course grade, the project participation and final course grade demonstrates general student behavior and attitudes towards assignments in general, and their final accomplishment in the course. 
Table 2. Student participation in Lego Robot Project and final course grades in the two classes. ' $\mathrm{Y}$ ' indicates 'Yes' for participation. ' $\mathrm{N}$ ' indicates 'No' for non-participation.

\begin{tabular}{|c|c|c|c|c|c|}
\hline \multirow[b]{2}{*}{ Student } & \multicolumn{5}{|c|}{ LEGO ROBOT PROJECT } \\
\hline & $\begin{array}{c}\text { Concept } \\
\text { Map }\end{array}$ & Prelab & Demo & $\begin{array}{c}\text { Oral } \\
\text { Presentation }\end{array}$ & Report \\
\hline$\#$ & $10 \%$ & $10 \%$ & $20 \%$ & $20 \%$ & $40 \%$ \\
\hline 1 & $\mathrm{Y}$ & $\mathrm{Y}$ & $\mathrm{Y}$ & $\mathrm{Y}$ & $\mathrm{Y}$ \\
\hline 2 & $\mathrm{Y}$ & $\mathrm{Y}$ & $\mathrm{Y}$ & $\mathrm{Y}$ & $\mathrm{Y}$ \\
\hline 3 & $\mathrm{Y}$ & $\mathrm{Y}$ & $\mathrm{Y}$ & $\mathrm{Y}$ & $\mathrm{Y}$ \\
\hline 4 & $\mathrm{Y}$ & $\mathrm{Y}$ & $\mathrm{Y}$ & $\mathrm{Y}$ & $\mathrm{Y}$ \\
\hline 5 & $\mathrm{Y}$ & $\mathrm{Y}$ & $\mathrm{Y}$ & $\mathrm{Y}$ & $\mathrm{Y}$ \\
\hline 6 & $\mathrm{~N}$ & $\mathrm{Y}$ & $\mathrm{Y}$ & $\mathrm{Y}$ & $\mathrm{Y}$ \\
\hline 7 & $\mathrm{~N}$ & $\mathrm{Y}$ & $\mathrm{Y}$ & $\mathrm{Y}$ & $\mathrm{Y}$ \\
\hline 8 & $\mathrm{~N}$ & $\mathrm{Y}$ & $\mathrm{Y}$ & $\mathrm{Y}$ & $\mathrm{Y}$ \\
\hline 9 & $\mathrm{Y}$ & $\mathrm{Y}$ & $\mathrm{Y}$ & $\mathrm{Y}$ & $\mathrm{N}$ \\
\hline 10 & $\mathrm{Y}$ & $\mathrm{N}$ & $\mathrm{Y}$ & $\mathrm{Y}$ & $\mathrm{N}$ \\
\hline 11 & $\mathrm{Y}$ & $\mathrm{Y}$ & $\mathrm{Y}$ & $\mathrm{Y}$ & $\mathrm{Y}$ \\
\hline 12 & $\mathrm{~N}$ & $\mathrm{~N}$ & $Y$ & $Y$ & $Y$ \\
\hline 13 & $\mathrm{~N}$ & $\mathrm{~N}$ & $\mathrm{Y}$ & $\mathrm{Y}$ & $\mathrm{N}$ \\
\hline 14 & $\mathrm{~N}$ & $\mathrm{~N}$ & $\mathrm{Y}$ & $\mathrm{Y}$ & $\mathrm{N}$ \\
\hline 15 & $\mathrm{~N}$ & $\mathrm{~N}$ & $\mathrm{Y}$ & $\mathrm{Y}$ & $\mathrm{N}$ \\
\hline 16 & $\mathrm{~N}$ & $\mathrm{~N}$ & $\mathrm{Y}$ & $\mathrm{Y}$ & $\mathrm{N}$ \\
\hline 17 & $\mathrm{~N}$ & $\mathrm{~N}$ & $\mathrm{Y}$ & $\mathrm{Y}$ & $\mathrm{N}$ \\
\hline 18 & $\mathrm{~N}$ & $\mathrm{~N}$ & $\mathrm{Y}$ & $\mathrm{N}$ & $\mathrm{N}$ \\
\hline 19 & $\mathrm{~N}$ & $\mathrm{~N}$ & $\mathrm{~N}$ & $\mathrm{~N}$ & $\mathrm{~N}$ \\
\hline
\end{tabular}

\begin{tabular}{|c|}
\hline $\begin{array}{c}\text { FINAL } \\
\text { COURSE } \\
\text { GRADE }\end{array}$ \\
\hline \\
\hline A \\
\hline$A$ \\
\hline$A$ \\
\hline$A$ \\
\hline$A$ \\
\hline$A$ \\
\hline$A$ \\
\hline$A$ \\
\hline$A$ \\
\hline$A$ \\
\hline$B$ \\
\hline$B$ \\
\hline$B$ \\
\hline$B$ \\
\hline$C$ \\
\hline$C$ \\
\hline$C$ \\
\hline$D$ \\
\hline$D$ \\
\hline
\end{tabular}

\section{Discussion of Results}

The Lego Robot Project was introduced close to the end of the semester in late October. One student indicated in the course evaluation form that there was too much work crammed at the end of the semester, and that the Lego Robot Project required work outside the classroom. Considering the time and effort required for this project, the contribution of this project to total course grade has since been raised to $10 \%$ from $5 \%$.

The project should also probably be spread over four weeks instead of three weeks. The extra week will give the inexperienced students extra time to perform the necessary research investigation, to design and program the robot, troubleshoot to correct design and programming errors, and finally produce a working robot.

Some students did not participate in some or all of the project components. Several reasons can be attributed to student attitudes towards the project; in line with the abovementioned student's comment, some students might have considered this project too time consuming for its weight and contribution to the overall course grade. 
It is apparent that the administration of the Lego Robot Project has room for improvement. However, the success rate among students who did participate in the subassignments is clear, showing the effectiveness of this project, the peer-led teams and concept maps in capturing interest of multiple student types, and achieving project and related course outcomes.

\section{Summary and Conclusion}

Four new Lego robot projects with varying difficulty levels have been developed to meet the needs of all students with different educational background, experience with robotics and robot kits, work experience, and goals. The projects were undertaken by teams of two or three students. Each team had a peer leader from among the team members. In addition, a peer leader from a sophomore class with extensive experience in Lego Robot kits was invited as an external peer-leader. Peer-leading was conducted informally in this first realization of the project. Concept maps were introduced to connect project activities to project learning outcomes and show the students how the project learning outcomes met the course learning outcomes.

The Lego Robot Project comprised 5\% of the final course grade, and consisted of subassignments including prelabs (10\%), elaboration on concept maps (10\%), robot demos (20\%), oral presentations (20\%), and final project report (40\%). The concept maps were well received. Some students indicated that the concept map skeleton provided by the instructor was so clear that they did not know what to add in the assignment, and chose not to participate. Almost all students participated in the robot demos and oral presentations, further hinting to the idea that students enjoy hands-on activities, as expected of engineering and engineering technology students. Students not participating in some of the project sub-assignments exhibited similar behaviors in the rest of the course (general attitude towards assignments; incomplete assignments).

The overall student enthusiasm for the Lego Robot Project suggests that this project was able to capture the interest of the students of various backgrounds, particularly in the design, programming, building, and presentation (oral and working robot demonstration) components of the project, all of which were in-classroom activities (see Figure 3.) The project was successful in engaging students in learning activities, such as learning from peers and hands-on experiences. The hands-on and in-class aspects of the project were appealing to both traditional and non-traditional students. Participation in the prelab write-up, expansion and extension of concept maps, and the final report write-up (all outside-classroom activities) was less than desired.

The lack of participation in writing-oriented exercises clearly demonstrates where the interest of students lie (creating, designing, programming, working with their hands, and less on writing). Assignments with writing components need further student engagement, and must be investigated further. In the new administration of the course, the score weights of these components have been doubled to motivate students to participate. In any case, the concept maps were covered by the instructor in detail in the classroom, 
although some students chose not to work on the take-home assignment. The students addressed the concepts and their interrelation in their oral PowerPoint presentations, demonstrating the contribution of concept maps to the students' learning, and their understanding of how the activities relate to the learning outcomes.

Overall, the Lego Robot Project was a successful project in helping students to attain the learning outcomes of the course.

\section{Future Work}

The next step in this project is to organize more structured peer-led team activities to capitalize on the students' experiences, and allow greater input into the administration and content of the labs ${ }^{10,11}$. In addition, concept maps should be introduced outside the project, and allow the students to come up with their own concept map initially, before introducing a skeleton and then a more complete concept map to avoid confusion of expectations among students.

\section{Acknowledgement}

This project has been partially funded by NSF Grant \#0737526. The author thanks Diego Rojas for his contribution to the preparation of the new Lego Robot Project.

\section{Bibliography}

1. Joseph D. Novak, Learning, Creating and Using Knowledge: Concept Maps as Facilitative Tools in Schools and Corporations, Mahwah, NJ: Lawrence Erlbaum Assoc., 1998.

2. Joan M. T. Walker and Paul H. King, "Concept Mapping as a Form of Student Assessment and Instruction in the Domain of Bioengineering," J. of Engineering Education, pp. 167-179, Apr. 2003.

3. Joseph D. Novak and D. Bob Gowin, Learning How to Learn, p13, Cambridge University Press, 1984.

4. Mary Besterfield-Sacre, Jessica Gerchak, MaryRose Lyons, Larry J. Shuman and Harvey Wolfe, "Scoring Concept Maps: An Integrated Rubric for Assessing Engineering Education," Journal of Engineering Education, pp.105-115, April 2004.

5. Micheal Kramer, "Can Concept Maps Bridge the Engineering TGap", in Crosslink, The Aerospace Corporation magazine of advances in aerospace, Vol 8,No1, Spring 2007. (Available: http://www.aero.org/publications/crosslink/spring2007/05.html)

6. Rasha Morsi, Wael Ibrahim and Frances Williams, "Concept Maps: Development and Validation of Engineering Curricula," $37^{\text {th }}$ ASEE/IEEE Frontiers in Education Conference, October 10-13, 2007, pp. T3H-18 - T3H-21.

7. Dietrich Altert and Christina M. Steiner, "Empirical Validation of Concept Maps: Preliminary Methodological Consideerations," Proc. Of the Fifth IEEE Internation Conf. on Advanced Learning Technologies,pp 1-2, 2005.

8. Pei-Chi Sue, Jui-Feng Weng, Jun-Ming Su and Shian-Shyong Tseng, "A New Approach for Constructing the Concept Map," Proc. of the IEEE International Conference on Advanced Learning Technologies, 20004.

9. S. Miertschin, D. Benhaddou, C. Willis and F. Attarzadeh, "Using Interactive Concept Maps to Enhance Learning and Thinking Skills,"Proc. 2007 ASEE Gulf-Southwest Annual Conference, T2B6, South Padre Island, Texas, March 2007.

10. V. Roth, E. Goldstein and G. Marcus, Peer-Led Team Learning, A Handbook for Team Leaders: The Workshop Project, Upper Saddle River: Prentice Hall, 2001. 
11. D. K. Gosser, M. S. Cracolice, J. A. Kampmeier, V. Roth, V. S. Strozak, and P. Varma-Nelson, PeerLed Team Learning, A Guidebook: The Workshop Project, Upper Saddle River: Prentice Hall, 2001.

12. Robert J. Pond and Jeffrey L. Rankinen, Introduction to Engineering Technology, $7^{\text {th }}$ Ed., Prentice Hall, 2009. 